\title{
Desempenho de cabras em lactação alimentadas com dietas com concentrado a base de feno da parte aérea da mandioca
}

\author{
Novais, D.L. ${ }^{1}$; Leite, L.C. ${ }^{2}$; Eiras, C.E. ${ }^{3}$; Leite, M.C.P. ${ }^{2}$ e Queiroz, M.A.A. ${ }^{4}$
}

\author{
Universidade Federal da Bahia. Salvador. BA. Brasil. \\ 2Universidade Federal do Recôncavo da Bahia. Cruz das Almas, BA. Brasil. \\ ${ }^{3}$ Universidade Estadual de Maringá. Maringá. PR. Brasil. \\ ${ }^{4}$ Universidade Federal do Vale do São Francisco. Petrolina. PE. Brasil.
}

\section{PalaVRas ChaVe adicionaIS}

Gordura.

Manihot esculenta Crantz.

Produção de leite.

Proteína.

\section{RESUMO}

Objetivou-se avaliar o efeito do feno da parte aérea da mandioca (FAM) em diferentes níveis na dieta sobre o consumo, digestibilidade, produção e composição físico-química do leite de cabra. Foram utilizadas oito cabras multíparas, da raça Parda Alpina, com peso corporal de $51,0 \pm 6,2 \mathrm{~kg}$, aproximadamente 120 dias de lactação. Os animais foram distribuídos aleatoriamente em um quadrado latino $4 \times 4$ duplicado, com três teores de FAM na dieta total: 5, 10 e $15 \%$; além do controle (0\%). A dieta foi composta por milho, farelo de soja, FAM e feno de Tifton. A variação nos teores de FAM nas dietas de cabras em lactação não apresentou efeito sobre os consumos de matéria seca e nutrientes. Não houve efeito sobre a digestibilidade aparente da MS $(64,99 \%)$ e $M O(66,9 \%)$ das dietas. Houve redução na digestibilidade da fibra e da proteína bruta. Não houve efeito das dietas para a produção de leite em $\mathrm{kg} / \mathrm{d}$ e produção de leite corrigida para $3,5 \%$. A concentração e a produção diária de gordura não foram influenciadas. Houve aumento nos teores de proteína, lactose, sólidos totais e extrato seco desengordurado $(\mathrm{g} / \mathrm{d})$ do leite em comparação à dieta controle. O feno da parte aérea da mandioca pode ser utilizado em até $15 \%$ da MS não interferindo nos consumos de matéria seca e nutrientes e produção de leite, porém reduz a digestibilidade da fibra pela redução de volumoso da dieta.

Performance of lactating goats fed protein concentrate from aerial part of cassava SUMMARY

\section{ADDITIONAL KEYWORDS}

Fat.

Manihot esculenta Crantz.

Milk yield performance.

Protein.

\section{INFORMACIÓN}

Cronología del artículo.

Recibido/Received: 9.9.2014

Aceptado/Accepted: 1.9.2015

On-line: 10.12.2015

Correspondencia a los autores/Contact e-mail:

daylaggo@hotmail.com

\section{INTRODUÇÃO}

Um dos enfoques da pecuária atual é a busca de fontes alimentares alternativas para a formulação de dietas para os animais (Azevedo et al., 2006). Geralmente, os suplementos proteicos, como o farelo de soja, apresentam preços elevados e contribuem para aumentar o custo com alimentação (Mendes et al., 2010), sendo necessária a utilização de recursos regionais disponíveis que possam ser inseridos na alimentação de ruminantes, tornando as rações menos onerosas.
A mandioca (Manihot esculenta Crantz.) é de grande importância para a América Tropical, sendo cultivada e consumida principalmente por pequenos produtores rurais em áreas com solos com baixa fertilidade, onde as condições climáticas são desfavoráveis à exploração de outras culturas (Ferreira et al., 2009). Na última safra, a produção brasileira de mandioca foi de 23,1 milhões de toneladas, sendo a região Nordeste a segunda maior produtora nacional, com 5,66 milhões de toneladas (IBGE, 2015). 
Tabela I. Composição ( \% MS) dos ingredientes das dietas experimentais (Dry matter chemical composition of ingredients used in the experimental diets).

\begin{tabular}{lrcrc}
\hline & Milho & Farelo de soja & FAM & Feno de Tifton 85 \\
\hline MS & 89,71 & 88,98 & 85,33 & 89,72 \\
MM & 1,52 & 7,97 & 6,98 & 9,50 \\
MO & 98,48 & 92,03 & 93,02 & 90,50 \\
PB & 9,70 & 46,67 & 24,98 & 9,32 \\
EE & 3,17 & 0,83 & 3,43 & 1,49 \\
FDN & 9,40 & 18,20 & 62,88 & 79,38 \\
FDA & 3,48 & 7,33 & 29,64 & 33,18 \\
LDA & - & - & 18,36 & 16,06 \\
CT & 85,61 & 44,54 & 64,61 & 79,69 \\
CNF & 76,21 & 26,34 & 1,73 & 0,31 \\
\hline
\end{tabular}

$\mathrm{MS}=$ matéria seca; $\mathrm{MM}=$ matéria mineral; $\mathrm{MO}=$ matéria orgânica; $\mathrm{PB}=$ proteína bruta; $\mathrm{EE}=$ extrato etéreo; $\mathrm{FDN}=$ fibra em detergente neutro; FDA= fibra em detergente ácido; $L D A=$ lignina em detergente ácido; $\mathrm{CT}=$ carboidratos totais; $\mathrm{CNF}=$ carboidratos não-fibrosos $\mathrm{FAM}=$ feno da parte aérea da mandioca.

Tabela II. Composição percentual dos ingredientes e a composição bromatologica das dietas experimentais (Proportion of ingredients and chemical composition of experimental diets).

\begin{tabular}{|c|c|c|c|c|}
\hline \multirow{2}{*}{ Itens } & \multicolumn{4}{|c|}{ FAM (níveis de inclusão \%) } \\
\hline & 0 & 5 & 10 & 15 \\
\hline \multicolumn{5}{|l|}{ Ingredientes ( \%) } \\
\hline Feno de tifton & 61,90 & 56,40 & 43,50 & 38,80 \\
\hline Milho & 25,60 & 27,37 & 35,65 & 37,99 \\
\hline Farelo de soja & 11,32 & 10,17 & 9,25 & 7,10 \\
\hline $\mathrm{FAM}^{2}$ & 0,00 & 4,84 & 10,27 & 14,69 \\
\hline Mistura mineral ${ }^{1}$ & 0,45 & 0,48 & 0,51 & 0,49 \\
\hline Calcário & 0,23 & 0,25 & 0,31 & 0,34 \\
\hline Fosfato bicálcico & 0,50 & 0,48 & 0,51 & 0,59 \\
\hline \multicolumn{5}{|l|}{ Composição nutricional ( \%) } \\
\hline MS & 88,58 & 88,35 & 88,00 & 87,75 \\
\hline $\mathrm{MO}$ & 91,65 & 91,87 & 92,54 & 92,73 \\
\hline PB & 13,53 & 13,87 & 14,39 & 14,28 \\
\hline EE & 1,83 & 1,96 & 2,21 & 2,35 \\
\hline $\mathrm{CT}$ & 76,29 & 76,04 & 75,94 & 76,10 \\
\hline CNF & 22,69 & 23,80 & 29,92 & 31,20 \\
\hline FDN & 53,60 & 52,24 & 46,02 & 44,90 \\
\hline FDA & 22,26 & 21,85 & 19,40 & 19,07 \\
\hline NIDA ( \% Nitrogênio total) & 11,36 & 12,15 & 12,18 & 12,96 \\
\hline NIDN ( \% Nitrogênio total) & 39,01 & 39,17 & 36,08 & 36,42 \\
\hline NDTest. & 57,27 & 58,28 & 62,90 & 63,68 \\
\hline
\end{tabular}

$\mathrm{FAM}=$ Feno da parte aérea da mandioca. ${ }^{1}$ Composição por kg do produto: Cálcio= $230 \mathrm{~g}$; Fósforo= $160 \mathrm{~g}$; Sódio= $102 \mathrm{~g}$; Enxofre $=5800 \mathrm{mg} ;$ Ferro $=1300 \mathrm{mg} ;$ Cobre $=1000 \mathrm{mg} ;$ Manganês $=800 \mathrm{mg}$; Zinco $=2680 \mathrm{mg}$; Cobalto $=100 \mathrm{mg}$; lodo $=77 \mathrm{mg}$; Magnésio $=2000 \mathrm{mg}$; Selênio= $15 \mathrm{mg}$.

Em um sistema de produção, o consumo de alimento é de grande importância, visto que a ingestão de matéria seca determina o fornecimento de nutrientes necessários para atender os requerimentos de mantença e produção dos animais (Carvalho et al., 2006). Resultados preliminares com a utilização da parte aérea da mandioca na dieta de ruminantes são obser- vados na literatura (Modesto et al., 2006; 2008; 2009; Gonçalves et al., 2008).

Desta forma, considera-se importante pesquisar fontes regionais de alimentos que levem à melhoria no desempenho animal que reduzam os custos de produção. Com isso, objetivou-se com essa pesquisa avaliar a influência da suplementação com feno da parte aérea da mandioca em diferentes níveis na dieta sobre o consumo, digestibilidade, produção e composição físico-química do leite de cabra.

\section{MATERIAL E MÉTODOS}

O ensaio experimental foi conduzido no setor de Caprinocultura da Universidade Federal do Recôncavo da Bahia - UFRB, Cruz das Almas - BA. O período experimental foi de 60 dias, entre os meses de abril a junho de 2011.

Foram utilizadas oito cabras multíparas, da raça Parda Alpina, com peso corporal de 51,0 $\pm 6,2 \mathrm{~kg}$, com aproximadamente 120 dias de lactação, confinadas em baias individuais, com dimensões 1,3 x 1,0 m, com piso ripado de madeira, providas de comedouros e bebedouros.

Os animais foram distribuídos aleatoriamente em quadrado latino $4 \times 4$ duplicado com quatro tratamentos, sendo: tratamento controle (0), 5, 10 e $15 \%$ de inclusão do feno da parte aérea da mandioca (FAM). O experimento foi constituído por quatro períodos de 15 dias, sendo dez dias para adaptação e cinco para as coletas de dados.

As rações experimentais foram balanceadas segundo o NRC (1981) para atender as exigências de mantença e lactação das cabras, desta forma, a inclusão do feno da parte aérea da mandioca na dieta levou a diferentes razões de concentrado e de volumoso na dieta total, sendo: 38:62 para o tratamento controle; 44:56 para 5\%; 56:44 para 10\% e 61:39 para 15\% de inclusão. Para a elaboração do FAM, houve um processo de desidratação e trituração com auxílio de equipamentos que são utilizados para confecção de chás. As dietas foram compostas de milho moído, farelo de soja e o FAM como concentrados e feno de Tifton 85 triturado como volumoso. A composição dos alimentos, a proporção dos ingredientes na dieta, bem como a composição das dietas experimentais encontram-se nas tabelas I e II.

As dietas foram fornecidas na forma de mistura completa, duas vezes ao dia (07:30 e 15:30 h), logo após as ordenhas da manhã e da tarde. Para isso, o feno de Tifton 85 foi picado em máquina forrageira estacionária (GTM-1001, Garthen Ind. e Comércio Ltda), obtendo-se partículas de 1 a $3 \mathrm{~cm}$, e armazenado em sacos plásticos. Após a trituração, todos os ingredientes foram pesados e misturados manualmente no cocho.

Com acesso ad libitum às rações, o consumo voluntário foi calculado pela diferença entre o oferecido e as sobras; para tanto, as sobras foram coletadas diariamente, pesadas e ajustadas para corresponderem a $10 \%$ do total oferecido. Para cada animal, constituíram-se amostras compostas de sobras, referentes a cada 
período experimental, as quais foram congeladas para posteriores análises.

As amostras dos alimentos e sobras foram acondicionadas em sacos plásticos e armazenadas em freezer com temperatura a $-18^{\circ} \mathrm{C}$. Ao término do período de coletas, as amostras foram descongeladas e, em seguida foi realizada a pré-secagem em estufa de ventilação forçada a $55^{\circ} \mathrm{C}$ por $72 \mathrm{~h}$, sendo trituradas em moinho de facas dotado de peneiras de crivo $1 \mathrm{~mm}$ de diâmetro, sendo os teores de matéria seca (MS), matéria orgânica $(\mathrm{MO})$, matéria mineral $(\mathrm{MM})$, proteína bruta $(\mathrm{PB})$, extrato etéreo (EE) e lignina $\left(\mathrm{H}_{2} \mathrm{SO}_{4} 72 \% \mathrm{p} / \mathrm{p}\right)$, nitrogênio insolúvel em detergente neutro (NIDN), nitrogênio insolúvel em detergente ácido (NIDA) obtidos seguindo os procedimentos descritos em Silva and Queiroz (2002); fibra em detergente neutro (FDN), fibra em detergente ácido (FDA), segundo as descrições de Van Soest et al. (1991) adaptado por Mertens (2002), utilizando-se $\alpha$-amilase termoestável. Os carboidratos totais (CT) e carboidratos não-fibrosos (CNF) foram estimados segundo Sniffen et al. (1992), como:

$$
\begin{aligned}
& \mathrm{CT}=100-(\% \mathrm{~PB}+\% \mathrm{EE}+\% \mathrm{MM}) \\
& \mathrm{CNF}=100-\% \mathrm{FDN}-\% \mathrm{~PB}-\% \mathrm{EE}-\% \mathrm{MM}
\end{aligned}
$$

$\mathrm{O}$ teor de nutrientes digestíveis totais (NDT) do feno de Tifton e dos concentrados foi estimado pelas equações de regressão descritas por Cappelle $e t$ al. (2001). A produção e a composição do leite de cada período foram estimadas com base em duas ordenhas diárias, realizadas de maneira manual, sendo calculadas pela soma da produção da ordenha realizada pela manhã e a tarde, durante os cinco dias consecutivos de coletas. Nas amostras de leite foram determinados os teores de gordura, proteína, lactose, sólidos totais e extrato seco desengordurado. As análises quantitativas do leite foram realizadas através do método infravermelho no Laboratório Clínica do Leite, da Escola Superior de Agricultura Luiz de Queiroz (ESALQ) em Piracicaba-SP. Para conversão da produção de leite para 3,5\%, utilizou-se a equação de Gaines (1928), sugerida pelo NRC (2001): LCG 3,5\% $=(0,4255 \times \mathrm{kg}$ de leite $)+[16,425 \times(\%$ gordura $/ 100) \times \mathrm{kg}$ de leite $]$.

Para estimativa dos coeficientes de digestibilidade aparente de MS, MO, PB e FDN, foram coletadas fezes dos animais, diretamente na porção final do reto, durante seis dias consecutivos para cada período, seguindo a seguinte distribuição: $1^{\circ}$ dia $(18: 00 \mathrm{~h}), 2^{\circ}$ dia (10:00 h), $3^{\circ}$ dia (12:00h), $4^{\circ}$ dia (14:00 h), $5^{\circ}$ dia (16:00 h) e $6^{\circ}$ dia $(8: 00 \mathrm{~h})$, antes de oferecer a dieta do período seguinte (Ítavo et al. 2002). As amostras de fezes foram armazenadas a $-10^{\circ} \mathrm{C}$ e, posteriormente, da mesma forma que os alimentos e sobras, foram processadas ao término de cada período experimental. A estimativa da produção fecal foi realizada utilizando-se a fibra em detergente neutro indigestível (FDNi) como indicador interno. As amostras de fezes, alimentos e sobras foram incubadas in situ utilizando sacos F57 (Ankom ${ }^{\circledR}$ ), por um período de 288 horas, segundo metodologia descrita por Detmann et al. (2012). A quantidade da amostra incubada foi de $100 \mathrm{~g} / \mathrm{m}^{2}$ para alimentos, sobras e fezes. O material remanescente da incubação
Tabela III. Consumo de matéria seca e de frações nutricionais por cabras em lactação alimentadas com dietas contendo feno da parte aérea da mandioca (Dry matter intake and nutritional fractions of lactating goats fed with diets containing aerial part of cassava).

\begin{tabular}{llllll}
\hline \multirow{2}{*}{ Variáveis } & \multicolumn{5}{c}{ FAM $(\%)$} \\
\cline { 2 - 5 } & \multicolumn{1}{c}{0} & \multicolumn{1}{c}{5} & 10 & 15 & \\
\hline CMS (kg/d) & 1,58 & 1,54 & 1,69 & 1,71 & 0,084 \\
CMS (\% PV) & 2,87 & 2,88 & 3,17 & 3,12 & 0,114 \\
CMO (kg/d) & 1,49 & 1,45 & 1,61 & 1,63 & 0,079 \\
CFDN (kg/d) & 0,754 & 0,728 & 0,732 & 0,711 & 0,033 \\
CFDN (\% PV) & 1,36 & 1,36 & 1,38 & 1,30 & 0,059 \\
CPB (kg/d) & 0,233 & 0,228 & 0,254 & 0,253 & 0,012 \\
\hline
\end{tabular}

$\mathrm{CMS}=$ consumo de matéria seca; $\mathrm{CMO}=$ consumo de matéria orgânica; $\mathrm{CFDN}=$ consumo de fibra em detergente neutro; $\mathrm{CPB}=$ consumo de proteína bruta. $E P M=$ erro padrão da média.

foi submetido à extração com detergente neutro e o resíduo considerado FDNi.

Os procedimentos estatísticos foram realizados com o auxílio do programa SAS (Statistical Analisys System, 2003). Foi utilizado o modelo misto (PROC MIXED) para avaliar as variáveis de desempenho, onde o tratamento, período e quadrado foram utilizados como efeitos fixos e o animal como efeito aleatório. Quando significativo, as médias dos tratamentos foram comparadas pelo teste de Tukey, adotando-se $5 \%$ como nível crítico de probabilidade.

\section{RESULTADOS E DISCUSSÃO}

A utilização do feno da parte aérea da mandioca (FAM) nas dietas de cabras em lactação (tabela III) não apresentou resposta $(\mathrm{p}>0,05)$ sobre o consumo de matéria seca (CMS). O CMS médio foi de $1,65 \mathrm{~kg} / \mathrm{dia}$, equivalente a $3,02 \%$ do peso vivo. O CMS encontra-se abaixo do sugerido pelo NRC (1981), que recomenda de 4 a $5 \%$ do PV para cabras desta categoria. É provável que este resultado seja decorrente do baixo nível de produção de leite $(0,651 \mathrm{~kg})$ das cabras devido ao adiantamento do período de lactação. Entretanto, de acordo com AFRC (1993), o CMS varia de 3 a 5\% do PV para animais produzindo cerca de $2 \mathrm{~L} /$ dia de leite. Como não houve efeito dos níveis de FAM sobre o CMS, acredita-se que os animais ingeriram nutrientes suficientes para atender suas exigências.

Apesar do FAM ter proporcionado redução dos níveis de FDN das dietas, não houve efeito $(p>0,05)$ do FAM sobre o consumo da fibra em detergente neutro (CFDN), obtendo-se uma média de $0,736 \mathrm{~kg} /$ dia (1,35\% PV). Branco et al. (2010b) ao avaliarem níveis de FDN proveniente da forragem $(19,27,35,42$ e $48 \%$ de FDN) na dieta de cabras lactantes (apesar de haver redução no CMS), não encontraram efeito sobre o CFDN. Segundo esses autores, a variação do FDN limitou o CFDN (0,71 kg/dia; 1,24\% PV), havendo repleção no trato digestório. O CFDN verificado no presente estudo corrobora com os autores citados, porém ainda não se sabe o CFDN ideal para caprinos, pois os dados publicados em trabalhos mais recentes não são 
Tabela IV. Digestibilidade aparente da matéria seca e das fraçóes nutricionais em cabras lactantes alimentadas com feno da parte aérea da mandioca (Apparent digestibility of dry matter and nutrient fractions in lactating goats fed from aerial part of cassava).

\begin{tabular}{|c|c|c|c|c|c|}
\hline \multirow{2}{*}{ Variáveis } & \multicolumn{4}{|c|}{ FAM ( \%) } & \multirow{2}{*}{ EPM } \\
\hline & 0 & 5 & 10 & 15 & \\
\hline MS & 69,06 & 66,42 & 64,68 & 61,54 & 1,51 \\
\hline MO & 70,60 & 68,35 & 66,62 & 63,65 & 1,44 \\
\hline FDN & $60,01^{a}$ & $57,32^{\mathrm{ab}}$ & $54,27^{\mathrm{ab}}$ & $49,96^{b}$ & 1,53 \\
\hline PB & $73,28^{a}$ & $68,33^{\text {ab }}$ & $64,43^{\text {ab }}$ & $59,62^{b}$ & 1,89 \\
\hline
\end{tabular}

$\mathrm{MS}=$ digestibilidade da matéria seca; $\mathrm{MO}=$ digestibilidade da matéria orgânica; FDN= digestibilidade da fibra em detergente neutro; $\mathrm{PB}=$ digestibilidade da proteína bruta.EPM= erro padrão da média. a,bMédias seguidas de letras diferentes, na linha, diferem estatisticamente $(p<0,05)$ pelo teste de Tukey.

Tabela V. Produção e composição de leite de cabras em lactação alimentadas com dietas com diferentes níveis de feno da parte aérea da mandioca (Production and composition of milk from lactating goats fed diets with different levels from aerial part of cassava).

\begin{tabular}{|c|c|c|c|c|c|}
\hline \multirow{2}{*}{ Variáveis } & \multicolumn{4}{|c|}{ FAM (\%) } & \multirow{2}{*}{ EPM } \\
\hline & 0 & 5 & 10 & 15 & \\
\hline $\mathrm{PL}$ (kg/dia) & 0,551 & 0,703 & 0,692 & 0,613 & 0,05 \\
\hline PLC $3,5 \%$ (kg/dia) & 0,707 & 0,704 & 0,640 & 0,578 & 0,05 \\
\hline Gordura $(g / d)$ & 20,8 & 25,0 & 24,4 & 21,3 & $<0,01$ \\
\hline Proteína (g/d) & $19,8^{b}$ & $25,2^{\mathrm{a}}$ & $24,6^{a}$ & $23,2^{\mathrm{ab}}$ & $<0,01$ \\
\hline Lactose $(\mathrm{g} / \mathrm{d})$ & $22,5^{b}$ & $31,2^{\mathrm{a}}$ & $30,5^{\mathrm{a}}$ & $28,7^{\mathrm{ab}}$ & $<0,01$ \\
\hline Sólidos totais $(\mathrm{g} / \mathrm{d})$ & $68,0^{\mathrm{b}}$ & $86,9^{a}$ & $85,6^{\mathrm{a}}$ & $79,2^{\mathrm{ab}}$ & 0,01 \\
\hline $\operatorname{ESD}(g / d)$ & $46,8^{b}$ & $61,9^{a}$ & $60,4^{a}$ & $57,3^{\mathrm{ab}}$ & $<0,01$ \\
\hline Gordura (\%) & 4,0 & 3,8 & 3,5 & 3,3 & 0,20 \\
\hline Proteína (\%) & 3,7 & 3,8 & 3,6 & 3,7 & 0,14 \\
\hline Lactose $(\%)$ & 4,1 & 4,4 & 4,3 & 4,3 & 0,07 \\
\hline Sólidos totais (\%) & 12,6 & 12,8 & 12,1 & 12,1 & 0,32 \\
\hline $\operatorname{ESD}(\%)$ & 8,6 & 9,0 & 8,6 & 8,8 & 0,15 \\
\hline
\end{tabular}

$\mathrm{PL}=$ produção de leite; $\mathrm{PLC}=$ produção de leite corrigida para gordura; $\mathrm{ESD}=$ extrato seco desengordurado. $\mathrm{EPM}=$ erro padrão da média. a,bMédias seguidas de letras diferentes, na linha, diferem estatisticamente $(p<0,05)$ pelo teste de Tukey.

numericamente suficientes para recomendar sobre a concentração de fibra nas dietas (Branco et al., 2010b).

Os consumos de matéria orgânica $(\mathrm{CMO})$ e proteína bruta (CPB) não alteraram ( $p>0,05)$ com a inclusão de FAM. A semelhança nos teores de $\mathrm{MO}, \mathrm{PB}$ e o CMS das dietas experimentais justificam os resultados obtidos. Araújo et al. (2009), não encontraram variações no CMO e CPB de cabras Moxotó recebendo diferentes níveis de feno de maniçoba, e relacionaram esses resultados as dietas serem isoprotéicas e CMS semelhantes.

Não houve efeito $(p>0,05)$ da inclusão do FAM sobre a digestibilidade aparente da MS (64,99\%) e MO $(66,90 \%)$ das dietas (tabela IV). Araújo et al. (2009) encontraram digestibilidade de $57,51 \%$ e $45,52 \%$ para MS e MO, respectivamente, para cabras alimentadas com níveis de feno de maniçoba (30, 40, 50 e 60\%). De maneira geral, os coeficientes de digestibilidade aparente desse estudo foram maiores quando comparados com os valores observados pela pesquisa supracitada.
A digestibilidade da FDN foi influenciada $(\mathrm{p}<0,05)$ pelos níveis de FAM, a adição de $15 \%$ reduziu a digestibilidade da fibra. Este resultado pode ser atribuído ao aumento dos teores de concentrado necessários à padronização dos níveis energéticos das dietas, o que pode ter causado aumento da taxa de passagem e consequentemente, reduções nos coeficientes de digestibilidade dos componentes da parede celular considerados de lenta digestão (Branco et al., 2010a).

Houve redução $(p<0,05)$ na digestibilidade da proteína bruta (DPB) para o nível de 15\% de FAM em relação ao tratamento controle $(0 \%)$. Como mencionado acima para a digestibilidade da fibra, o aumento da taxa de passagem também provocou a queda na digestibilidade da proteína. Além disso, houve aumento no NIDA (tabela II) com a inclusão do FAM na dieta, sendo esta fração dos compostos nitrogenados considerada indigestível (Sniffen et al., 1992). Parte do nitrogênio está ligado a fibra, e como houve redução na DFDN, naturalmente o nitrogênio ligado a fibra também foi afetado. Modesto et al. (2008), ao substituírem a silagem de milho pela silagem do terço superior da rama da mandioca $(0,20,40$ e $60 \%$ ) na dieta de vacas prenhes verificaram redução na digestibilidade da proteína e atribuíram esse resultado ao maior teor de NIDA nas dietas que continham silagem da rama de mandioca na dieta total.

Não houve efeito $(\mathrm{p}>0,05)$ da inclusão do FAM para a produção de leite em $\mathrm{kg} / \mathrm{d}$ e produção de leite corrigida (PLC) para 3,5\% (tabela V). A semelhança na produção do leite dos animais reflete o atendimento das necessidades nutricionais dos mesmos para a referida produção, além de que também não houve efeito sobre o consumo de MS e a produção de leite foi baixa devido ao estágio avançado de lactação das cabras.

Zambom et al. (2005) observaram redução na produção de leite de cabras aos 60 dias de lactação alimentadas com diferentes razões de volumoso e de concentrado (40:60; 50:50; 60:40; 70:30 e 80:20), esses resultados são justificados pela redução do nível de NDT das dietas $(85,84 ; 81,70 ; 77,56 ; 73,42$ e $68,28 \%$, respectivamente). A influência das dietas sobre a produção de leite são mais evidentes em animais com maior capacidade produtiva de leite quando comparado a cabras com menor produção (Goetsch et al., 2001), como no presente estudo.

A concentração e a produção diária de gordura não foram ( $p>0,05)$ influenciadas pelos níveis de inclusão, apresentando valores médios de 3,62\% e 23,3 g/dia, respectivamente. A concentração de gordura observada neste estudo é superior ao encontrado por Carvalho et al. (2006) ao avaliarem diferentes teores de fibra (20, 27, 34, 41 e $48 \%$ de FDN) na alimentação de cabras Alpinas aos 45 dias de lactação com produção de 3,88 kg de leite, os autores também não observaram efeito da dieta sobre a percentagem de gordura $(3,24 \%)$.

Neste estudo, a inclusão de FAM aumentou os teores de proteína, lactose, sólidos totais e extrato seco desengordurado $(\mathrm{g} / \mathrm{d})$ do leite em comparação à dieta controle. A diferença observada na produção diária dos componentes do leite pode ser atribuída à menor produção de leite (embora não significativa) do trata- 
mento controle em relação aos demais tratamentos. Como a variabilidade nos valores de composição do leite foi menor do que nos dados de produção de leite, foi possível observar o efeito significativo em alguns componentes do leite.

Segundo Costa et al. (2009), a composição do leite de cabra pode variar de acordo com diversos fatores, entre eles o período de lactação (a proporção dos constituintes lácteos é maior quando a produção de leite é menor), dieta, raça, ou ação combinada desses fatores nas condições ambientais de cada país ou região.

\section{CONCLUSÕES}

O feno da parte aérea da mandioca pode ser adicionado até $15 \%$ em dietas para cabras em estágio avançado de lactação.

\section{BIBLIOGRAFIA}

AFRC. 1993. Agricultural and Food Reaserch Council - Energy and protein requirements of ruminants. $C A B$ International. Wallingford. $159 \mathrm{pp}$.

Araújo, M.J.; Medeiros, A.N.; Silva, D.S.; Pimenta Filho, E.C.; Queiroga, R.C.R.E. e Mesquita, I.V.U. 2009. Produção e composição do leite de cabras Moxotó submetidas a dietas com feno de maniçoba (Manihot glaziovii Muell Arg.). Rev Bras Saúde Prod Anim, 10: 860-873.

Azevedo, E.B.; Nörnberg, J.L.; Kessler, J.D. Brüning, G.; David, D.B.; Falkenberg, J.R. e Chielle, Z.G. 2006. Silagem da parte aérea de cultivares de mandioca. Ciênc Rural, 36: 1902-1908.

Branco, R.H.; Rodrigues, M.T.; Rodrigues, C.A.F.; Silva, M.M.C.; Leão, M.I. e Pereira, V.V. 2010a. Efeito dos níveis de fibra em detergente neutro oriunda da forragem sobre a eficiência microbiana e os parâmetros digestivos em cabras leiteiras. Rev Bras Zootecn, 39: 372-381.

Branco, R.H.; Rodrigues, M.T.; Silva, M.M.C.; Rodrigues, C.A.F.; Queiroz, A.C. e Araújo, F.L. 2010b. Efeito dos níveis de fibra da forragem sobre - consumo, a produção e a eficiência de utilização de nutrientes em cabras lactantes. Rev Bras Zootecn, 39: 2477-2485.

Cappelle, E.R.; Valadares Filho, S.C.; Silva, J.F.C. e Cecon, P.R. 2001. Estimativas do valor energético a partir de características químicas e bromatológicas dos alimentos. Rev Bras Zootecn, 30: 1837-1856.

Carvalho, S.; Rodrigues, M.T.; Branco, R.H. e Rodrigues, C.A.F. 2006. Consumo de nutrientes, produção e composição do leite de cabras da raça Alpina alimentadas com dietas contendo diferentes teores de fibra. Rev Bras Zootecn, 35: 1154-1161.

Costa, R.G.; Queiroga, R.C.R.E. e Pereira, R.A.G. 2009. Influência do alimento na produção e qualidade do leite de cabra. Rev Bras Zootecn, 38: 307-321.

Goetsch, A.L.; Detweiler, G.; Sahlu, T.; Puchala R. and Dawson L.J. 2001. Dairy goat performance with different dietary concentrate levels in late lactation. Small Ruminant Res, 41: 117-125.
Gonçalves, G.S.; Oliveira, G.J.C.; Jaeger, S.M.P.L.;Oliveira, R.L.; Campos, J.O. e Rezende, L.S. 2008. Desempenho de cordeiros alimentados com dietas contendo sal forrageiro de espécies vegetais xerófitas. Rev Bras Zootecn, 37: 2185-2190.

IBGE. 2015. Instituto Brasileiro de Geografia e Estatística. Diretoria de Pesquisas, Coordenação de Agropecuária, Pesquisa da Pecuária Municipal. Brasil.

Detmann, E.; Valadares Filho, S.C.; Berchielli, T.T.; Cabral, L.S.; Ladeira, M.M.; Souza, M.A.; Queiroz, A.C.; Saliba, E.O.S.; Pina, D.S. e Azevedo, J.A.G. 2012. Métodos para análises de alimentos - INCT - Ciência Animal. Editora UFV. Viçosa, M.G. Brasil. 214 pp.

Ítavo, L.C.V.; Valadares Filho, S.C.; Silva, F.F.; Valadares, R.F.D.; Paulino, M.F.; Ílavo, C.C.B.F. e Moraes, E.H.B.K. 2002. Comparação de indicadores e metodologia de coleta para estimativas de produção fecal e fluxo de digesta em bovinos. Rev Bras Zootecn, 31: 1833-1839.

Mertens, D.R. 2002. Gravimetric determination of amylase-treated neutral detergent fiber in feeds with refluxing in beaker or crucibles: collaborative study. J AOAC Int, 85: 1217-1240.

Modesto, E.C.; Santos, G.T.; Jobim, C.C.; Cecato, U.; Silva, D.C. e Zambom, M.A. 2006. Inclusão de silagem de rama de mandioca na alimentação de vacas em lactação, mantidas em pasto de Cynodon: consumo e digestibilidade. Acta Sci Anim Sci, 28: 127-135.

Modesto, E.C.; Santos, G.T.; Zambom, M.A. Damasceno, J.C.; Branco, A.F. eVilela, D. 2008. Consumo, digestibilidade e parâmetros ruminais em vacas gestantes alimentadas com silagem de rama de mandioca. Rev Bras Zootecn, 37: 944-950.

Modesto, E.C.; Santos, G.T.; Damasceno, J.C.; Cecato, U.; Vilela, D.; Silva, D.C.; Souza, N.E. e Matsushita, M. 2009. Inclusão de silagem de rama de mandioca em substituição à pastagem na alimentação de vacas em lactação: produção, qualidade do leite e da gordura. Arq Bras Med Vet Zootec, 61: 174-181.

Mendes, C.Q.; Fernandes, R.H.R.; Susin, I.; Pires, A.V. e Gentil, R.S. 2010. Substituição parcial do farelo de soja por ureia ou amireia na alimentação de cabras em lactação. Rev Bras Zootecn, 39: 1818-1824.

NRC. 1981. National Reserarch Council-Nutrient requirements of dairy goats. National Academic Press. Washinton, D.C. 110 pp.

NRC. 2001. National Research Council-Nutrient requirements of dairy cattle. 7 ed. National Academic Press. Washinton, D.C. 381 pp.

Silva, D.J.; Queiroz, A.C. 2002. Análise de alimentos: métodos químicos e biológicos. UFV. Viçosa, M.G. 235 pp.

Sniffen, C.J.; O'connor, D.J.; Van Soest, P.J.; Fox, D.G. and Russel, J.B. 1992. A netcarbohydrate and protein system for evaluating cattle diets: carbohydrate and protein availability. J Anim Sci, 70: 3562-3577.

Van Soest, P.J.; Robertson, J.B. and Lewis, B.A. 1991. Methods for dietary fiber, neutral detergent fiber, and nonstarch polysaccharides in relation to animal nutrition. J Dairy Sci, 74: 3583-3597.

Zambom, M.A.; Alcalde, C.R.; Silva, K.T.; Macedo, F.A.F.; Santos, G.T.; Borghi, E.L. e Barbosa, E.D. 2005. Ingestão, digestibilidade das rações e produção de leite em cabras saanen submetidas a diferentes relações volumoso: concentrado na ração. Rev Bras Zootecn, 34: 2505-2514. 
